\title{
Erratum to: Operational earthquake loss forecasting: a retrospective analysis of some recent Italian seismic sequences
}

\author{
Eugenio Chioccarelli ${ }^{1} \cdot$ Iunio $^{\text {Iervolino }}{ }^{2}$
}

Published online: 21 January 2016

(C) Springer Science+Business Media Dordrecht 2016

\section{Erratum to: Bull Earthquake Eng DOI 10.1007/s10518-015-9837-8}

After the online publication of the paper, it was found a bug in the software processing the illustrative nationwide maps shown in Fig. 2. The corrected Fig. 2 is reported below. All the results and the conclusions of the study are not affected by this error, yet authors, who strive for the quality of their work, apologise.

The online version of the original article can be found under doi:10.1007/s10518-015-9837-8.

Iunio Iervolino

iunio.iervolino@unina.it

Eugenio Chioccarelli

eugenio.chioccarelli@amracenter.com

1 Analisi e Monitoraggio dei Rischi Ambientali (AMRA) scarl, via Nuova Agnano 11, 80125 Naples, Italy

2 Dipartimento di Strutture per l'Ingegneria e l'Architettura, Università degli Studi di Napoli Federico II, via Claudio 21, 80125 Naples, Italy 




$10^{\circ} \mathrm{E}$

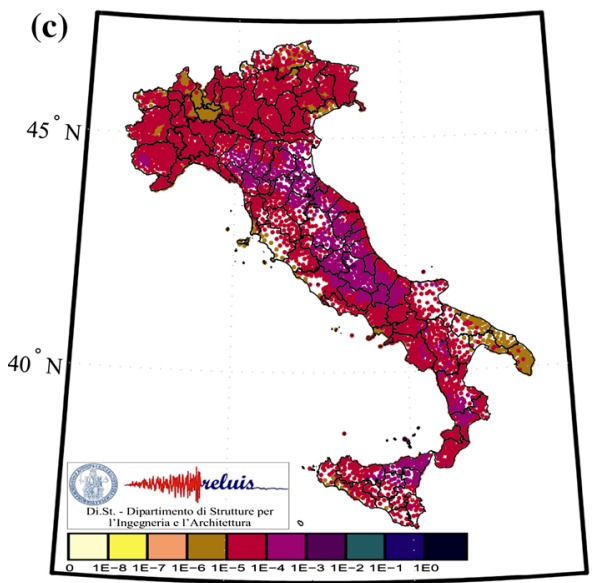

$10^{\circ} \mathrm{E}$
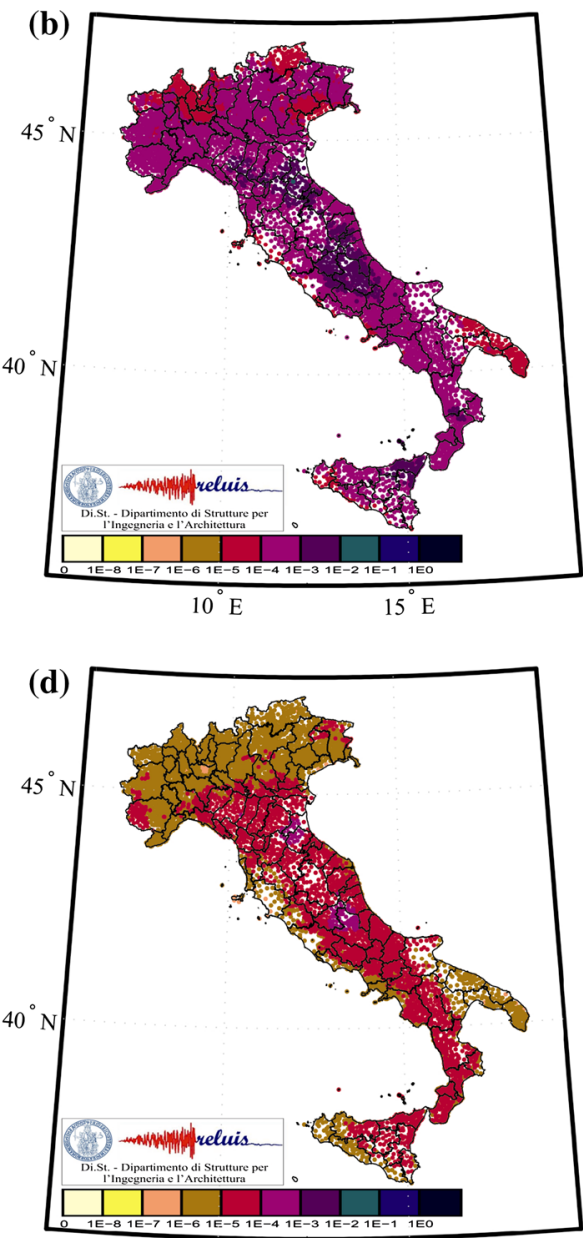

$15^{\circ} \mathrm{E}$

Fig. 2 Illustrative example of MANTIS-K outputs: maps of the expected values of a unusable and b collapsed buildings (per 100 municipality buildings), and the expected values of $\mathbf{c}$ injuries and $\mathbf{d}$ fatalities per 100 municipality residents. These results are computed using the OEF-Italy data of Fig. 1 as the input. Therefore, they refer to the week after 00:00 of 06/04/09 